DOI: $10.34185 / 1991-7848.2021 .01 .02$

УДК 621.771 .294

О.І. Бабаченко, Р.В. Подольський, К. Г. Дьоміна, Г.А. Кононенко, О.А. Сафронова ${ }^{2}$

\title{
ФІЗИЧНЕ І МАТЕМАТИЧНЕ МОДЕЛЮВАННЯ ГАРЯЧОЇ ПЛАСТИЧНОЇ ДЕФОРМАЦІЇ ЛАБОРАТОРНИХ ЗЛИТКІВ СТАЛЕЙ ДЛЯ ОСЕЙ
}

\begin{abstract}
Анотація. Проведено огляд досліджень у галузі моделювання процесів у металі під час термообробки та обробки металу тиском та вплив обробки на фізикомеханічні властивості сталі з хімічним складом 0,59\% , 0,31\% Si, 0,73\% Розроблено математичну модель розрахунку фізико-механічних властивостей сталі в процесі гарячої пластичної деформації. В результаті моделювання були отримані функції: величина деформації в напрямку прикладеної сили, поділена на початкову довжину матеріалу. Отримано коефіцієнт подовження матеріалу 3 фактичним хімічним складом при температурі $1250 \pm 10^{\circ} \mathrm{C}$, яка склав 0,32. При порівнянні значень навантаження, що було застосовано при ГПД в лабораторних умовах і отримано в результаті розрахунків з використанням розробленої моделі встановлено, що вони мають близькі значення 45 МПа. Цим підтверджується адекватність отриманої моделі.
\end{abstract}

Ключові слова: моделювання, напруження, геометрія, осі, плавка, фізикомеханічні властивості.

\section{Вступ}

За рахунок підвищення вантажності вагонів підвищується фактичне навантаження на вісь, а збільшення швидкості веде до зростання динамічного впливу колії та рухомого складу, а також числа зміни циклів напружень в одиницю часу, що викликає підвищення напружень в деталях вагонів і локомотивів, а також рейкового шляху. Все це визначає необхідність збільшення міцності та службової надійності вузлів і деталей рухомого складу [1, 2].

У зв'язку з швидким скороченням строків освоєння виробів у виробництві велике значення має використання електронної та розрахункової техніки. Тому провідні фірми застосовують гнучкі виробничі системи, які базуються на автоматизації всього життєвого циклу виробів [3]. Моделювання дозволяє суттєво скоротити витрати часу та матеріальних ресурсів при освоєнні нових видів продукції або вдосконаленні технології виробництва. Найпоширенішими програмами для моделювання процесів у металі при деформаційній та термічній обробці є такі: QForm, модуль Magics [4] програми Materialise, ANSYS, SOLIDWORKS.

(c) Бабаченко O.І., Подольський Р.В., Дьоміна К.Г., Кононенко Г.А., Сафронова О.А., 2021 


\section{Постановки мети і завдань дослідження}

Дослідженням впливу режимів деформації на пророблення структури готових виробів займалося багато видатних вчених у галузі прокатного виробництва та в галузі кувального виробництва [5, 6]. Інтенсифікація режимів деформації практично завжди позитивно позначається на проробленні внутрішніх ділянок виробів, що деформуються [7]. Для підвищення якості залізничних осей необхідно підвищувати деформаційну пророблюваність чорнової осі при ГПД. Для дослідження впливу гарячої пластичної деформації на структуру та властивості сталі для залізничних осей, в лабораторних умовах був виготовлений злиток сталі, що за хімічним станом відповідає складу сталі для залізничних осей марки ОС згідно ДСТУ ГОСТ 31334:2009.

\section{Матеріал і методика досліджень}

В умовах Інституту чорної металургії була виконана виплавка дослідної плавки. Виплавку виконували за допомогою комплексної установки, що складається 3 плавильного агрегату ITПE-0,01 закритого типу i високочастотного джерела струму ВТГ-20-22, що має вбудовану станцію автономного охолодження. Загальний вигляд комплексної експериментальної установки показано на рис. 1. Ця установка дозволяє виплавляти в лабораторних умовах дослідні сталі, в тому числі спеціально леговані марганцем, кремнієм, хромом, молібденом та ін.

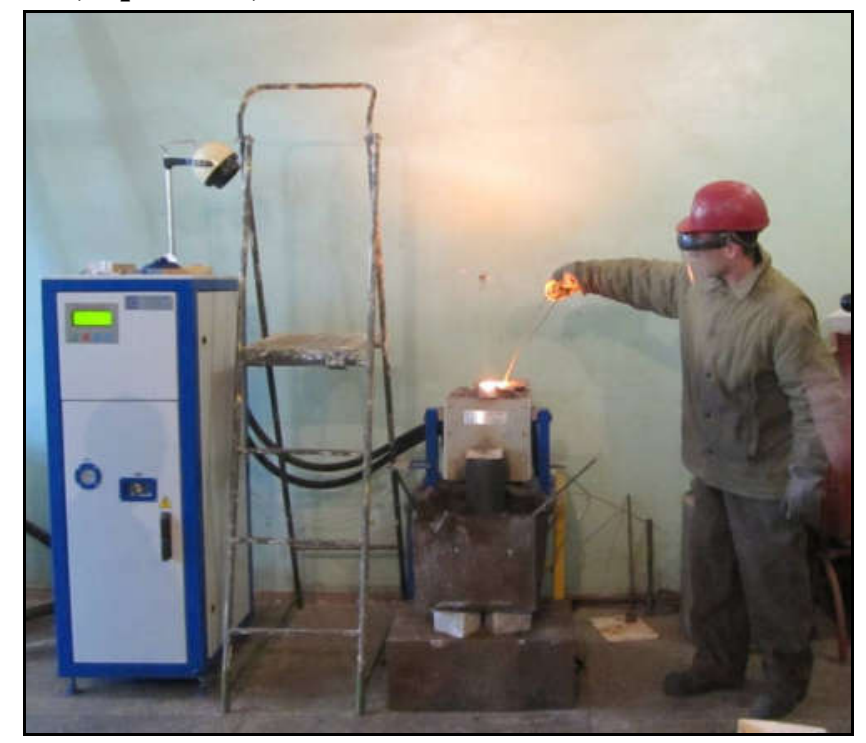

Рисунок 1 - Процес розплавлення сталі

Для забезпечення необхідних показників в досліджуваних варіантах $\mathrm{i}$ відсутності небажаних домішок присутніх в рядовому брухті в якості вихідної сировини вибрали метал колісної марки класу С - вуглецева якісна сталь 3 вмістом вуглецю $0,72 \%$, мас. 
Плавку проводили методом переплавлювання без примусового окислення домішок. 3 огляду на малий обсяг печі (до 12 кг), і той факт, що діаметр тигля становить всього близько 43 мм шихту подрібнювали до розмірів 10х7,5х5 мм, попередньо відпустивши метал в муфельній печі. Фактичний хімічний склад представлений в таблиці 1.

Таблиця 1

Фактичний хімічний склад лабораторної осьової плавки

\begin{tabular}{|l|l|l|l|l|l|l|l|l|l|}
\hline $\mathrm{C}$ & $\mathrm{Si}$ & $\mathrm{Mn}$ & $\mathrm{Cr}$ & $\mathrm{Ni}$ & $\mathrm{Mo}$ & $\mathrm{Al}$ & $\mathrm{Cu}$ & $\mathrm{V}$ & $\mathrm{Ti}$ \\
\hline 0,59 & 0,31 & 0,73 & 0,057 & 0,087 & 0,008 & 0,01 & 0,141 & 0,002 & 0,002 \\
\hline
\end{tabular}

Дослідження мікроструктури дослідного злитку в литому стані (рис. 2) проводилось за допомогою витравлення в 4\% розчині ніталя та гарячому розчині пікрату натрію. Мікроструктура - ферито-перлітна $з$ перлітом різної дисперсності. Дендритна структура, яка виявляється по слідах хімічної неоднорідності, характеризує процеси кристалізації. 3 рисунків видно вплив швидкості охолодження при кристалізації в залежності від відстані до поверхні виливниці (поверхня, 1/2 радіусу, центр) на дисперсність первинних кристалів.
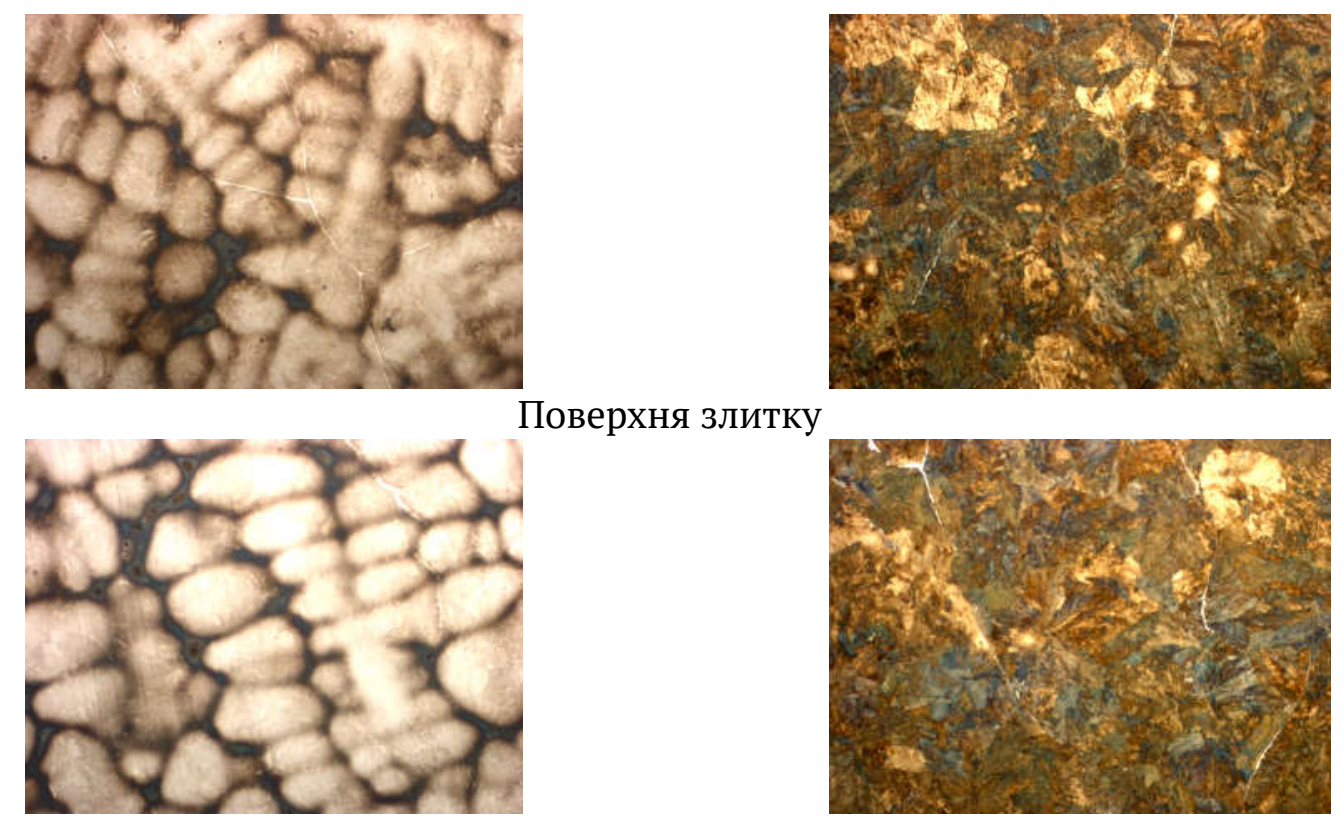

Поверхня злитку
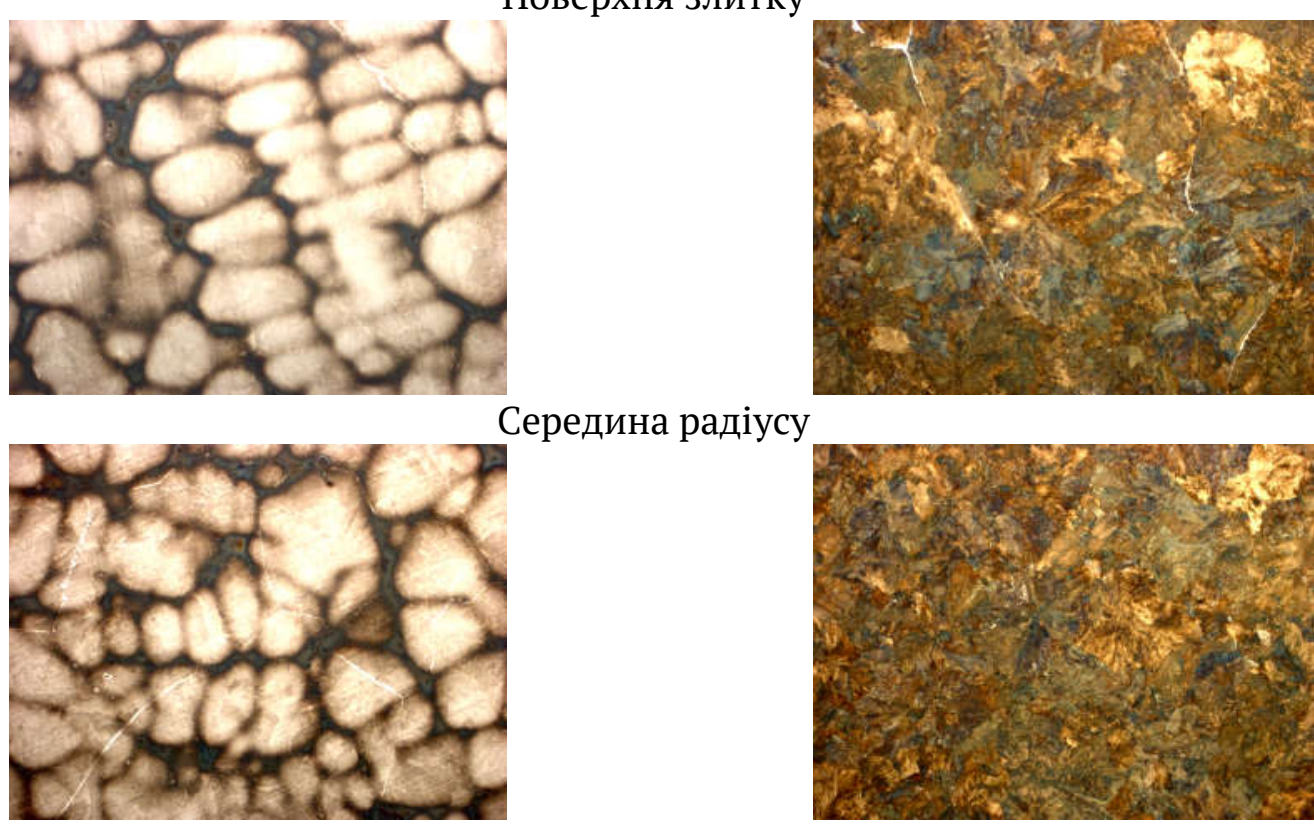

Середина радіусу

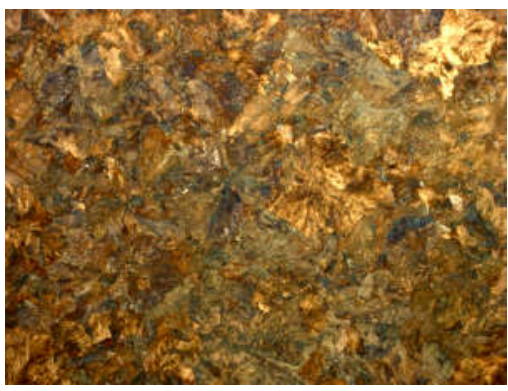

Центральна зона

Рисунок 2 - Мікроструктура лабораторного осьового злитку в литому стані, $\times 100$ 
Механічні властивості металу, визначаються його структурою. Найбільш ефективним способом підвищення властивостей металу $\epsilon$ зниження розміру зерна. Подрібнення дійсного зерна практично не впливає на характеристики міцності середьо- і високовуглецевої сталі, але чинить позитивний вплив на її пластичність [8].

Також гаряча деформація зменшує стійкість аустеніту в перлітній області і збільшує швидкість перлітного перетворення, в результаті чого утворюється високодисперсний перліт. Інтенсифікуючий вплив гарячої деформації на перлітне перетворення проявляється тим сильніше, чим вище ступінь обтиску [9].

Завданням досліджень була розробка моделі розрахунку розподілу фізико-механічних властивостей сталі для залізничних осей при ГПД на $50 \%$ по перерізу циліндричних зразків (124,9ммхØ31мм) в програмі QForm. Також було проведено деформацію зразків в лабораторних умовах на універсальній випробувальній машині.

B програмі QForm проводилось моделювання експерименту процесу гарячої пластичної деформації (ГПД) на $50 \%$ циліндричних зразків лабораторних осьових плавок для дослідження зміни морфології литої структури.

В якості вихідних умов задавалися типи операцій - розрахунок термопружно-пластичної задачі. Побудова геометрії зразка проводилося в програмі КОМПАС. Креслення експортувалося в форматі *.stp в QForm. Температура деформації встановлена $1250^{\circ} \mathrm{C}$. Показано процес зміни інтенсивності напруження в матеріалі при ГПД, середнє напруження та пластична деформація (рис. 3).
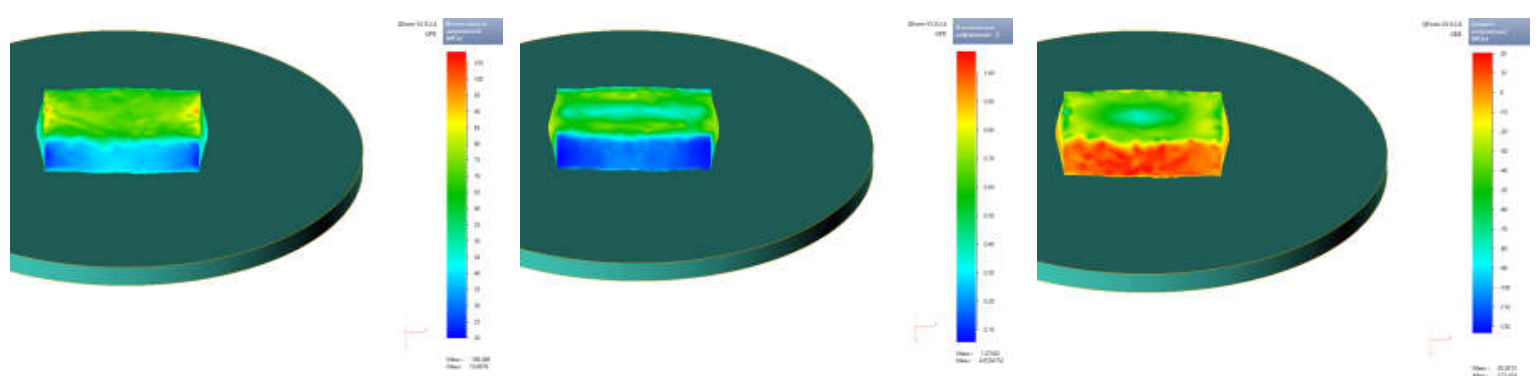

Рисунок 3 - Моделювання гарячої пластичної деформації проби з лабораторного злитка сталі для залізничних осей в робочому просторі QForm

На підставі даного моделювання отриманні результати по інтенсивності напруження, які склали близько 45-50 МПа, та розподіл напруження по зразку дослідної сталі для залізничних осей, які склали близько 40-50 МПа в області контакту з інструментом та близько 10-15 МПа в безконтактній області. 
В результаті моделювання були отримані функції: величина деформації в напрямку прикладеної сили, поділена на початкову довжину матеріалу. Отримано коефіцієнт подовження матеріалу з фактичним хімічним складом при температурі $1250 \pm 10^{\circ} \mathrm{C}$, яка склала 0,32. Отримано фізичну величину, яка представляє силу на одиницю площі в оточенні матеріальної точки на реальній поверхні або зображенні суцільного середовища. Отримано значення напружень в області контакту з інструментом близько 44,76 МПа.

у лабораторних умовах була проведена гаряча пластична деформація проби діаметром 31 мм та висотою 124 мм 3 дослідного злитку шляхом осаджування на величину 50\% (рис. 4). Температура нагрівання проб під гарячу деформацію дорівнювала $1250^{\circ} \mathrm{C}$. В результаті експерименту отримано фактичні значення напружень в області контакту з інструментом близько 46 МПа.

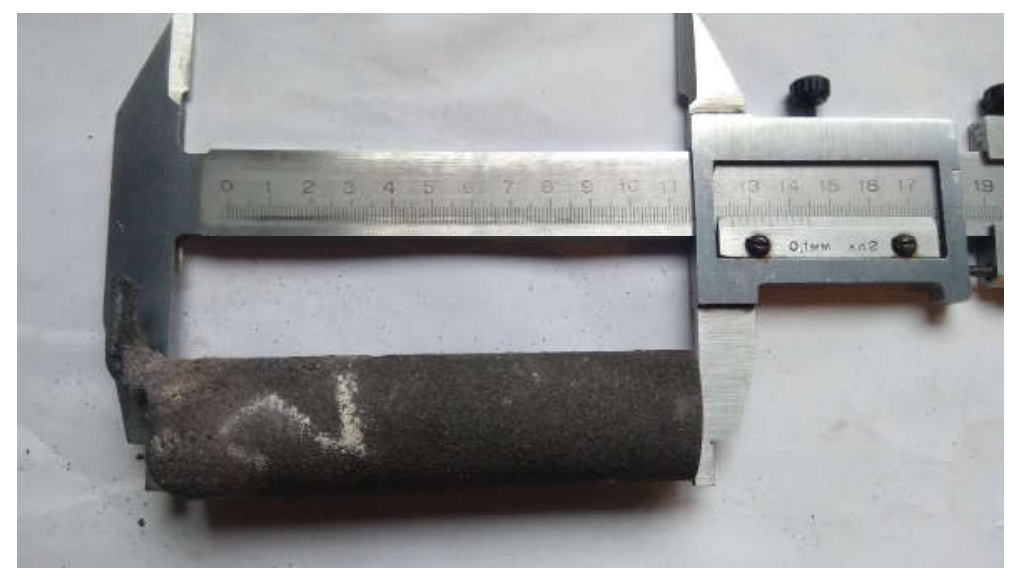

Рисунок 4 - Загальний вигляд проб з дослідного злитку до деформації

Мікроструктура досліджуваної лабораторної плавки після ГПД складається в основному з ферито- перлітної структури, спостерігались ділянки з грубою пластинчастою структурою перліту (рис. 5). Дослідження дендритної структури показало витяжку дендритів в області 1/2 радіусу та центральної частини, що підтверджує сприятливий вплив на рівномірність структури. Рівномірність структури досягалась завдяки впливу гарячої пластичної деформації, яка вирівнює негативні наслідки литого стану.

При порівнянні значень навантаження, що було застосовано при ГПД в лабораторних умовах і отриманого в результаті розрахунків з використанням розробленої моделі встановлено, що вони мають близькі значення 45 МПа. Цим підтверджується адекватність отриманої моделі. 

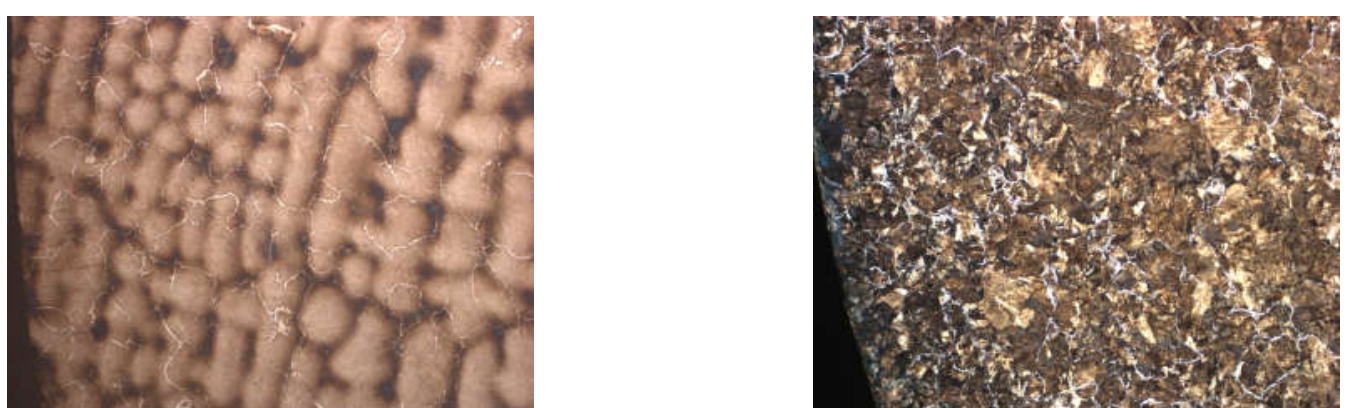

Поверхня злитку
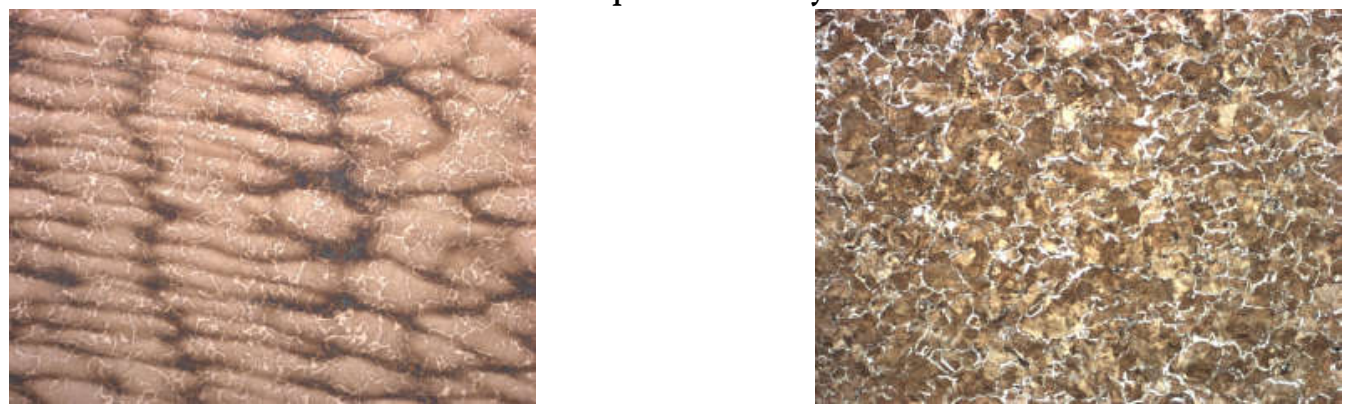

Середина радіусу
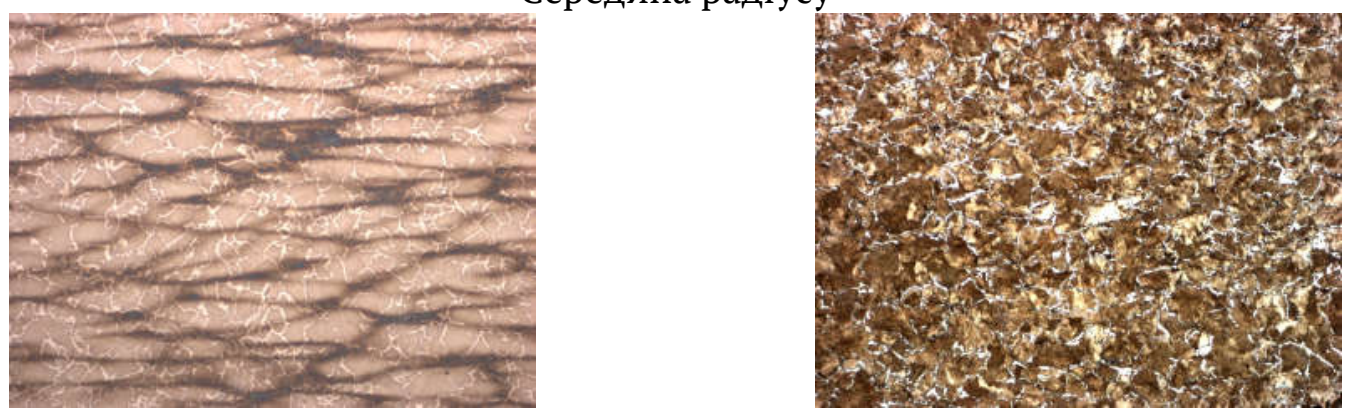

Центральна зона

Рисунок 5 - Мікроструктура лабораторного осьового злитку після ГПД, ×100

В подальшому отримані результати будуть використані про розробці моделі розрахунку зміни фізико-механічних властивостей металу залізничної осі при розробці перспективних способів та режимів її ГПД.

\section{ВИСНОВОК}

1. Проведено моделювання гарячої пластичної деформації на 50\% лабораторного осьового злитку при температурі $1250 \pm 10^{\circ} \mathrm{C}$ з хімічним складом 0,59\% , 0,31\% Si, 0,73\%Mn. Визначено коефіцієнт подовження матеріалу, який склав 0,32 .

2. Дослідження дендритної структури показало витяжку дендритів в області $1 / 2$ радіусу та центральної частини, що підтверджує сприятливий вплив на рівномірність структури.

\section{ЛIТЕРАТУРА}

1. Школьник Л.М. Повышение прочности осей подвижного состава / Л.М. Школьник. - М.: Транспорт, 1964. - 224 с. 
2. Safronova O., Podolskyi R., Domina K. Hereditary influence of the initial structural state on the quality of rail axes. The 19 International students scientific conference "Engineer of the Third Millennium". 2020. №19. C. 32-33. DOI: 10.13140/RG.2.2.24462.38728

3. Кундас С.П., Кашко ТА. Компьютерное моделирование технологических систем: Учеб, пособ. в 2 ч. Ч 1. Ми.: БГУИР, 2002. 164 с.

4. Аджамский С. В., Кононенко А. А., Подольский Р. В. Симуляция влияния остаточных напряжений и параметров SLM-технологии на формирование области границ изделия из жаропрочного никелевого сплава inconel 718. Матеріали міжнародної науково-технічної конференції «Інформаційні технології в металургії та машинобудуванні» Днепр, 2020, С. 46. DOI: https://doi.org/10.34185/1991-7848.itmm.2020.01.001.

5. Чекмарёв А. П. Теория прокатки крупных слитков / А. П. Чекмарёв, В. Л. Павлов, В. И. Мелешко, В. А. Токарев. - М.: Металлургия, 1968. - 252 с.

6. Дзугутов М. Я. Пластическая деформация высоколегированных сталей и сплавов / М. Я. Дзугутов. - М.: Металлургия, 1977. - 480 с.

7. Babachenko O. I., Diomina K. H., Kononenko H. A., Podolskyi R. V. Analysis of the influence of deformation working of a continuous billet on macro- and microstructure of structural steel (review). Physical Metallurgy and Heat Treatment of Metals. 2020. 91,№4. P. 17-29. DOI: https://doi.org/10.30838/J.PMHTM.2413.241120.17.687

8. Узлов И.Г., Бабаченко А.И., Дементьева Ж.А. Исследование влияния действительного зерна на износостойкость и сопротивление хрупкому разрушению углеродистой стали // Металлургическая и горная промышленность. - 2002. - №5. - С. 52 - 54.

9. В.И. Большаков, И.Е. Долженков, В.И. Долженков Термическая обработка стали и металлопроката. - Днепропетровск: Gaudeamus, 2002. -271 с.

\section{REFERENCES}

1. Sterin I.S. /Mashinostroitelnyie materialyi. Osnovyi metallovedeniya i termicheskoy obrabotki/ Uch. Posobie. - SPb.: Politehnika, 2003.-344 s. ISBN 5-7325-0636-5

2. Safronova O., Podolskyi R., Domina K. Hereditary influence of the initial structural state on the quality of rail axes. The 19 International students scientific conference "Engineer of the Third Millennium". 2020. №19. S. 32-33. DOI: 10.13140/RG.2.2.24462.38728

3. Kundas S.P., Kashko TA. Komp'juternoe modelirovanie tehnologicheskih sistem: Ucheb, posob. v 2 ch. Ch 1. Mi.: BGUIR, 2002. $164 \mathrm{~s}$.

4. Adzhamskij S. V., Kononenko A. A., Podol'skij R. V. (2020). Simuljacija vlijanija ostatochnyh naprjazhenij i parametrov SLM-tehnologii na formirovanie oblasti granic izdelija iz zharoprochnogo nikelevogo splava inconel 718. Materiali mizhnarodnoï naukovo-tehnichnoï konferenciï «Informacijni tehnologiï v metalurgiï ta mashinobuduvanni» Dnepr, S. 4-6. DOI: https://doi.org/10.34185/1991-7848.itmm.2020.01.001

5. Chekmarjov A. P. Teorija prokatki krupnyh slitkov / A. P. Chekmarjov, V. L. Pavlov, V. I. Meleshko, V. A. Tokarev. - M.: Metallurgija, 1968. - $252 \mathrm{~s}$.

6. Dzugutov M. Ja. Plasticheskaja deformacija vysokolegirovannyh stalej i splavov / M. Ja. Dzugutov. - M.: Metallurgija, 1977. - 480 s.

7. Babachenko O. I., Diomina K. H., Kononenko H. A., Podolskyi R. V. Analysis of the influence of deformation working of a continuous billet on macro- and microstructure of structural steel (review). Physical Metallurgy and Heat Treatment of Metals. 2020. 91,№4. P. 17-29. DOI: https://doi.org/10.30838/J.PMHTM.2413.241120.17.687

8. Uzlov I.G., Babachenko A.I., Dement'eva Zh.A. Issledovanie vlijanija dejstvitel'nogo zerna na iznosostojkost' i soprotivlenie hrupkomu razrusheniju uglerodistoj stali // Metallurgicheskaja i gornaja promyshlennost'. - 2002. - №5. - S. 52 - 54.

9. V.I. Bol'shakov, I.E. Dolzhenkov, V.I. Dolzhenkov Termicheskaja obrabotka stali i metalloprokata. - Dnepropetrovsk: Gaudeamus, 2002. -271 s. 
UDC 621.771.294

O. Babachenko, R. Podolskyi, K. Domina, G. Kononenko, O. Safronova

\section{PHYSICAL AND MATHEMATICAL MODELING OF HOT PLASTIC DEFORMATION OF LABORATOR STEEL INGOLES FOR AXES}

A review of research in the field of modeling processes in metal during heat treatment and pressure treatment of metal and the effect of processing on the physical and mechanical properties of steel with a chemical composition of $0.59 \% \mathrm{C}, 0.31 \% \mathrm{Si}, 0.73 \% \mathrm{Mn}$. A mathematical model for calculating the physical and mechanical properties of steel in the process of hot plastic deformation has been developed. As a result of modeling, the following functions were obtained: the amount of deformation in the direction of the applied force divided by the initial length of the material. The coefficient of elongation of the material with the actual chemical composition at a temperature of $1250 \pm 10^{\circ} \mathrm{C}$, which was 0.32 . In the laboratory, hot plastic deformation of the sample with a diameter of $31 \mathrm{~mm}$ and a height of $124 \mathrm{~mm}$ from the test ingot by deposition of 50\% When comparing the values of the load applied to the GPA in the laboratory they have close values of $\sim 45 \mathrm{MPa}$. The microstructure of the studied laboratory smelting after GPA consists mainly of ferritoperlite structure, areas with a rough lamellar structure of perlite were observed. The study of the dendritic structure showed the extraction of dendrites in the area of $1 / 2$ radius and the central part, which confirms the favorable effect on the uniformity of the structure. This confirms the adequacy of the obtained model. In the future, the obtained results will be used to develop a model for calculating the change in physical and mechanical properties of the metal of the railway axis in the development of promising methods and modes of its GPA.

Keywords: modeling, stress, geometry, axis, melting, physical and mechanical properties.

Бабаченко Олександр Іванович - докт. техн.наук, директор, Інститут чорної металургії ім. 3.І. Некрасова НАН України.

Подольський Ростислав Вячеславович - інженер першої категорії, Інститут чорної металургії ім. 3.І. Некрасова НАН України.

Дьоміна Катерина Генадіївна - канд. техн. наук, старший науковий співробітник, Інститут чорної металургії ім. 3.І. Некрасова НАН України.

Кононенко Ганна Андріївна - канд. техн. наук, вчений секретар, Інститут чорної металургії ім. 3.І. Некрасова НАН України.

Сафронова Олена Анатоліївна - інженер першої категорії, Інститут чорної металургії ім. 3.I. Некрасова НАН України.

Бабаченко Александр Иванович - докт. техн.наук, директор, Институт черной металлургии им. 3.И. Некрасова НАН Украины.

Подольский Ростислав Вячеславович - инженер первой категории, Институт черной металлургии им. 3.И. Некрасова НАН Украины. 
Демина Екатерина Геннадиевна - канд. техн.наук, старший научный сотрудник, Институт черной металлургии им. З.И. Некрасова НАН Украины.

Кононенко Анна Андреевна - канд. техн.наук, ученый секретар, Институт черной металлургии им. 3.И. Некрасова НАН Украины.

Сафронова Елена Анатольевна - инженер первой категории, Институт черной металлургии им. 3.И. Некрасова НАН Украины.

Babachenko Alexander- Dr. Technical Sciences, Director, Z. I. Nekrasov Iron \& Steel Institute of NAS of Ukraine.

Podolskyi Rostislav - engineer of the first category, Z. I. Nekrasov Iron \& Steel Institute of NAS of Ukraine.

Domina Kateryna - Cand. technical science, senior researcher, Z. I. Nekrasov Iron \& Steel Institute of NAS of Ukraine.

Kononenko Ganna - Cand. technical science, scientific secretary, Z. I. Nekrasov Iron \& Steel Institute of NAS of Ukraine.

Safronova Olena - engineer of the first category, Z. I. Nekrasov Iron \& Steel Institute of NAS of Ukraine. 